Collection: COST Action FP0905

"Biosafety of forest transgenic trees and EU policy directives"

Guest Editors: Cristina Vettori, Matthias Fladung

\section{Risk assessment of GM trees in the EU: current regulatory framework and guidance}

\author{
Jaime Aguilera $^{(1)}$, Kaare Magne Nielsen ${ }^{(2-3)}$, Jeremy Sweet ${ }^{(4)}$
}

The use of genetically modified organisms - their release into the environment, import, and utilisation as food/feed or food/feed ingredients - is regulated in the European Union (EU). For placing onto the market, current legislations require a comprehensive and science-based risk assessment. This risk assessment (RA) is performed by applicants and then evaluated by national authorities in close cooperation with the European Food Safety Authority (EFSA). The EFSA Panel on Genetically Modified Organisms (GMO) has published a comprehensive set of guidance documents for applicants and risk assessors for the RA of GM plants (GMP), their products for food and/or feed use, and their cultivation. In those documents, the strategy and the criteria to conduct the assessment are explained, as well as the scientific data to be provided by the applicant. The assessment starts with the molecular characterisation of the GMP. If the GMP or products derived from it are to be consumed, the evaluation of its composition, potential toxicity and/or allergenicity, and nutritional value constitute further cornerstones of the process. The environmental risk assessment (ERA) considers biotic and abiotic interactions and the impacts of the management of the GM plant when it is intended for cultivation. In the case of GM trees special emphasis would be placed on assessing their characteristic features such as their longevity, ability to disperse and their ecological significance in a range of environments. The outcome of the assessment is reflected in a published opinion from the EFSA GMO panel that indicates whether the GMP and its products raise any safety issues. This scientific opinion constitutes one of the elements taken into account by the different European regulatory authorities prior to a decision regarding authorisation to commercialise the product.

Keywords: GM Trees, Genetically Modified, Transgenic, Recombinant DNA, Risk Identification, Risk Characterization, Exposure Assessment

\section{Introduction}

Two genetically modified trees (GMTs) have been commercialised outside Europe and the application of genetic modification techniques to trees is currently at an advanced stage of research in the EU, with experimental field trials in some countries (Fladung 2011, Walter et al. 2010). Traits introduced to GMTs include modification of lignin and cellulose composition, optimised biomass for biofuel production and resistance to pests and diseases, among others (Harfouche et al. 2011, 2012). Hence, GM technology is expected to be part of the toolbox for the future breeding of trees for agriculture and forestry use.

Apart from the expected benefits, the cultivation and use of GMTs may have environment impacts where the GMT and its products are released. These impacts can be caused by the new trait conferred to the GMT and/or by the recombinant DNA/transgenes introduced. For instance, if the trans- genes are not part of the gene pool of the tree species and they transfer to wild counterparts, relatives or to other species, they may impact other biota and ecosystems. In addition, the genetic modification might lead to unintended changes in the characteristics of the modified tree that can also affect the environment. If the intended use of the GMT is agricultural (e.g., fruit trees) there is also a potential for changes to the food safety characteristics of the products derived from it.

Different national and international authorities have established regulations to ensure the safe use of GMOs, including GMTs (Kikuchi et al. 2008). In addition, there are internationally agreed standards (OECD 2012a, Codex Alimentarius 2009) on how to assess the potential health and environmental risks caused by such organisms. In the European Union (EU), different legal documents regulate all aspects related to GMOs including their safety assessment, labelling, marketing, transport, sampling and detection, $\square$ (1) European Food Safety Authority (EFSA), v. Carlo Magno 1/a, I-43126 Parma (Italy); (2) Department of Pharmacy, Faculty of Health Sciences, University of Tromsø, N9037 Tromsø (Norway); (3) Genøk-Center for Biosafety, Science Park, N9024 Tromsø (Norway); (4) Sweet Environmental Consultants, 6 Green Street, Willingham, CB24 5JA Cambridge (UK)

@) Jaime Aguilera

(jaime.aguilera@efsa.europa.eu)

Received: Dec 19, 2012 - Accepted: Mar 01, 2013

Citation: Aguilera J, Nielsen KM, Sweet J, 2013. Risk assessment of GM trees in the EU: current regulatory framework and guidance. iForest 6: 127-131 [online 2013-04-08] URL: http://www.sisef.it/iforest/contents/? id=ifor0101-006

Communicated by: Gabriele Bucci

and post-market environmental monitoring. In accordance with relevant legislation, the European Food Safety Authority (EFSA) assesses all GMO applications for marketing and or cultivation in the EU. Here we review the existing regulatory framework and the principles governing the risk assessment of GM plants in the EU, with special focus on GMTs. We highlight particularities of GMT that may require particular considerations in the assessment, and for which further guidance might be needed.

\section{Regulatory framework}

Among the existing legal mechanisms affecting GMOs in the EU, there are two legislations that focus specifically on safety issues. These are Directive 2001/18/EC on the deliberate release into the environment of GMOs (EC 2001) hereafter referred to as the "GMO Directive", and Regulation (EC) No $1829 / 2003$ on genetically modified food and feed (EC 2003), the "GM FF Regulation"[1]. For GM plants such as trees, the scope of the GMO Directive includes environmental safety issues derived from cultivation practices, but also covers other cases of (unintended) release as a consequence of the transport and processing of seeds or other parts of the plant. The GM FF Regulation attends to food and feed consisting of, containing or derived from GM plants, and covers food and feed safety issues, as well as environmental risks potentially posed by such food and feed.

As common principals, these two legislations establish that in the EU, products that are, contain, or are produced from GMOs must: (i) be subjected to a risk assessment prior to authorisation; (ii) be safe for hu- 
mans, animals and the environment; and (iii) gain an authorisation to be placed into the market. Those who intend to release or market a GM plant or derived product must submit an application, being the main part of it a dossier that compiles all the scientific data necessary to characterise the risks, followed by a safety assessment. Then, EFSA and the Competent Authorities of Member States (MSs) undertake a re-evaluation of the information and the assessment submitted by the applicant. If the GM plant in question is intended to be both cultivated and used for food/feed purposes, a single application under the GM FF Regulation, containing all the data requested by both legislations, will be enough to pursue authorisation under both the GMO Directive and the GMFF Regulation. Authorisations are valid for 10 years. After this period, permit holders must submit a new application (including a new dossier, which will be again evaluated) in order to pursue a renewal for another 10 years.

\section{Cultivation of GMTs for non-food and feed purposes}

The use of GMTs for forestry and other purposes not involving food or feed is regulated by the GMO Directive as mentioned above. The Directive considers two types of deliberate releases: those for placing the product on the EU market (e.g., cultivation) and those for experimental purposes (field trials). In the latter case, both the assessment of the application and the authorisation occur at national level only, and will not be covered in this review.

In case of cultivation (or of any other way of placing the GMT in the market), applications must include an must include an environmental risk assessment (ERA), whose structure is outlined in the Directive. EFSA (2009) has provided specific guidance to applicants on the "ERA" of the cultivation of plants for non-food/feed use which complements the guidance for the risk assessment of the cultivation of plants for food and feed use (EFSA 2010) and the Guidance on the risk assessment of GM plants for food and feed (EFSA 2011a). These documents provide detailed guidance on the data required for the ERA of GM plants intended for cultivation (see below). Applications must be submitted to a MS. The Competent Authority (CA) of this MS assesses the application, with the possibility to request to the applicant additional information it deems necessary to complete the evaluation. Then, the MS issues an assessment report on whether the GMO should be placed on the market and under which conditions. This MS report is distributed by the EC to all other MSs, who can raise comments or reasoned objections. If there are no objections or the objections can be solved between the MSs them- selves, then the MS who received the application takes a decision on the authorisation, which would apply to the rest of the MSs by mutual recognition. In case of reasoned objections that cannot be resolved between the MSs, the application is forwarded to EFSA, who conducts a further assessment and issues an opinion on the safety of the GM plant. EFSA is also empowered to ask the applicant for further information as needed. Finally, EFSA issues a scientific opinion on the ERA, which is sent, together with the initial ERA report of the lead MS, opinions and comments of the MS, to the European Commission (DG SANCO). The opinion is then considered by the EC, who (assisted by the MSs) decides on whether to authorise the cultivation of the GMT.

\section{Cultivation of GMTs for food/feed purposes}

When the GMT or its products are destined to enter the food chain (e.g., fruits), applications should be submitted under the GM FF Regulation. In addition to the ERA, such dossiers must also contain a safety assessment of the food and/or feed derived from the GMT. In this case, the application is forwarded directly to EFSA, who delegates to one MS the task to do the initial evaluation of the ERA submitted in the dossier. In addition, EFSA makes the full application available to all MSs for comments. Then, taking into account the assessment report of the delegated MS and all the comments received from the MSs, EFSA performs an assessment of the application that covers both food/feed and environmental safety issues, and publishes its scientific opinion with its conclusions. All opinions of the EFSA Panels are published and freely available in the EFSA journal (http://www.efsa.europa.eu/ en/publications/efsajournal.htm). Likewise for non-food/feed cases, the EFSA opinion is considered by the EC and the MSs for their decision on whether to authorise the GMT for both cultivation and food/feed use.

\section{Key principles of the GMO risk assessment}

The principles of risk assessment of GMOs and the different steps in the ERA are outlined in the GMO Directive and its implementing guidelines (EC 2002). The starting point of the ERA is the identification of the characteristics of the GMO that are different from the corresponding non-modified organism (conventional counterpart), and the evaluation of the potential adverse effects of such differences. This principle, known as the comparative approach, is internationally accepted as a useful starting point for the risk assessment of GMOs (OECD 2012a). The ERA should also be transparent and scientifically sound, i.e., based on scientific evidence obtained through experiments, from laboratory tests to field trials. All uncertainties identified and assumptions made should be clearly stated. Moreover, the ERA should be conducted case-by-case, taking into account the particularities of each GMO and its intended uses, which will determine the nature and extent of the information needed. Finally, the ERA should take into account direct, indirect, immediate and delayed effects of the GMO, as well as cumulative long-term effects, which would be caused by the accumulation of effects during long periods of time.

\section{The six steps of the ERA}

Based on the above principles, the ERA should be constructed following six steps:

(1) identification of the characteristics of the GMO, which may cause adverse effects (hazard identification);

(2) evaluation of the potential consequences of each adverse effect (hazard characterisation);

(3) evaluation of the likelihood of the occurrence of each potential adverse effect (exposure assessment);

(4) estimation of the risk posed by each identified characteristic (risk characterisation);

(5) application of management strategies for the characterised risks, and

(6) determination of the overall risk of the GMO.

After conducting the ERA, the applicant should conclude on the potential environmental impact of the GMO, in terms of invasiveness, gene transfer, effects on target and not-target organisms, effects on humans, animals, and biogeochemical processes, and impacts on cultivation and crop management techniques.

\section{Available guidance in the $\mathbf{E U}$}

In order to provide details on how the risk assessment of GM plants should be performed by the applicant, the EFSA GMO Panel has produced a set of guidance documents that cover in detail different aspects of the assessment, identify methodology and criteria to be followed, and provide rationales for the data requirements (http://www.efsa.europa.eu/en/gmo/gmoguid ance.htm). The most relevant are the Guidance on the environmental risk assessment of GM plants (EFSA 2010), the Guidance for risk assessment of food and feed from GM plants (EFSA 2011a); and the Guidance on the ERA of the cultivation of GM plants for non-food/feed purposes (EFSA 2009), which are developed to support in the preparation and evaluation of applications.

Guidance documents on the environmental risk assessment of GM plants for cultivation

These documents (EFSA 2009, 2010), 
hereafter referred as the "ERA Guidances", provide guidance for assessing the potential effects of GM plants on the environment via their cultivation and also through the transport and processing of imported plant material not cultivated in the EU. These Guidances are relevant for GM tree applications under the GMO Directive, and also for applications submitted under the GM FF Regulation if the GM tree and its products are intended for food/feed uses and for plant-derived products and timber products such as chemicals, biofuels or paper.

\section{Seven areas of concern in the ERA}

Based on the potential risks outlined in the GMO Directive, the ERA Guidance document identifies seven specific areas of concern to be addressed in the assessment, which are as follows:

(1) persistence and invasiveness including plant-to-plant gene flow;

(2) plant to microorganisms gene transfer;

(3) interactions of the GM plant with target organisms;

(4) interactions of the GM plant with non-target organisms (NTO);

(5) impacts on the specific cultivation, management and harvesting techniques;

(6) effects on biogeochemical processes;

(7) effects on human and animal health.

Each specific area of concern is developed in a structured and systematic way through the six steps of the ERA as described in the GMO Directive (see above); with indications on the information to be provided. In addition, the ERA guidance document considers cross-cutting issues to be taken into account in a horizontal manner during the assessment of each area of concern. These issues include the choice of the comparator (non-modified plant), the receiving environment(s), the statistical principles for the analyses, the longterm effects, and the particularities of GM plants containing stacked transformation events, for cases where relevant.

\section{Guidance for risk assessment of food and feed from GM plants}

This document hereafter named the "FF Guidance" is focused on food and feed consisting of, containing, or derived from GM plants, and is relevant for applications under the GM FF Regulation. Some parts of this document are also relevant for the ERA of the GM plants, such as the molecular characterisation of the genetic modification, and the compositional, phenotypic and agronomic analyses. Cross-references between the two documents are provided where necessary.

The FF Guidance presents in depth the general principles of the risk assessment of GM plants and how they should be applied for products within its scope. As for the ERA, the comparative approach is recog- nised as the best principle for the safety assessment of GM plant-derived food/feed products. This principle should therefore be applied for the assessment of the intended effects of the genetic modification, and also for the detection and evaluation of any possible unintended effects. The document also provides guidance on the choice of the appropriate comparator. In addition to this comparator, the FF Guidance recommends the use of a set of commercial non-GM reference varieties, in order to estimate the range of natural variation of the different endpoints to be compared. The compositional and phenotypic parameters to be analysed are described in detail, as well as the optimal design of the field trials and the statistical tests to be applied for the comparisons. For cases where the comparative approach is not possible, alternative strategies are proposed. Particular guidance is also given on how to structure the assessment of stacked events, including sub-combinations of events in cases where 3 or more unlinked inserts are present in the GM plant.

The FF Guidance covers all aspects of the safety of food and feed products that should be evaluated, such as potential changes in toxicity, allergenicity, and nutritional composition. Animal feeding trials for toxicological studies are recommended on a case-bycase basis, depending of the outcome of the molecular characterisation and the compositional, agronomic and phenotypic analyses. Guidance is provided on when and how to assess the toxicity of either the newly expressed protein, other constituents of the GM plant, or the whole GM food or feed. Depending on the scope of the recommended study, the FF Guidance refers to the appropriate protocol for toxicological test according to the OECD (2012b). For the assessment of allergenicity, a weight-of-evidence approach is recommended, and considerations are given to the currently available methods to obtain relevant data. With respect to nutrition, both the nutritional relevance of the newly expressed protein(s) and any possible change in the levels of endogenous constituents of the GM plant should be considered in the light of normal dietary exposure; or any intended alteration of use of the GM food or feed. On a case-by-case basis, guidance is provided on possible livestock studies to be performed with model or target species.

\section{Post-market environmental monitoring}

The GMO Directive establishes that, once a GMO is authorised for marketing, it must be monitored on a yearly basis. Therefore, applications under the GMO Directive (and under the GMFF Regulation when cultivation is foreseen) must be accompanied by a post-market environmental monitoring
(PMEM) plan outlining how the potential environmental effects of the GMO will be monitored.

The PMEM has two objectives:

(1) confirm that any assumptions regarding the occurrence and impact of potential adverse effects of the GMO or its use in the ERA are correct;

(2) identify the occurrence of adverse effects of the GMO or its use on human health or the environment which were not anticipated in the ERA.

The first objective is directly dependent on the outcome of the ERA, and therefore is to be fulfilled on a case-by-case basis. If, after conducting the ERA, there is still significant level of uncertainty or risks are identified, a case-specific monitoring (CSM) plan needs to be provided. This CSM will enable studies to be conducted on the cultivated plants to provide more information on the potential risks identified in the ERA, to reduce the level of uncertainty and to evaluate the efficiency of any management measures that might be applied to minimise the identified risks. The second objective is mandatory for all GMOs, and requires a strategy for general surveillance (GS) of the GMO, once released into the environment. The ERA Guidance Documents and the Guidance on the PMEM of GM plants (EFSA 2011b) provide information on designing CSM and GS studies in order to achieve the objectives of PMEM. Plans for CSM are hypothesis-driven based on the identified uncertainties and knowledge gaps of the ERA, and should therefore be designed to obtain the necessary data. GS is not hypothesis-driven, and therefore more difficult to plan. The Guidance proposes GS to be considered within a framework of general environmental protection monitoring, focusing on defined protection goals. Different tools and approaches to implement a plan for GS are discussed in the Guidance documents, starting from a comprehensive review of the existing scientific knowledge, to surveys to farmers and monitoring systems for environmental data collection.

\section{Challenges to the RA of GM trees}

Although applications for marketing of GM trees in the EU are not expected in the near future, it seems that they can be expected within the next decade. Although GM trees will be a novelty in the EU landscape of biotechnological applications, the already existing EU regulatory system will provide applicants, risk assessors and risk managers with adequate legislation and useful guidance. However some of the data requirements for the risk assessments in the EFSA guidances have been formulated with a view on GM annual crops, as these are the subjects of almost all applications already submitted or expected to be submitted to the EU in the near future. However, trees have seve- 
ral characteristics that differ from crop plants and can influence some of the data requirements for the risk assessment, for which more focused guidance might be needed Trees are generally perennial, woody, long lived species with long life cycles taking several years to reach sexual maturity and commence reproduction. When mature some can produce large amounts of seed and pollen that can disperse over long distances (Hoenicka \& Fladung 2006).

The type and purpose of the tree cultivation will influence the specific aspects to be considered in the ERA, and therefore the information requirements. In case of forest and plantation trees, species are not normally "domesticated" so that the cultivated types can be similar to wild types and exchange genes with them (DiFazio et al. 2004). In addition, forest trees can come in many forms that are adapted to a range of environments. They can form pioneer and climax vegetations and exist as a range of different components in environments. Furthermore, they have complex interactions with a range of biota often supporting large diverse communities and food webs (Whitham et al. 2006). They also have important roles in geographical and physical features of landscapes e.g., in stabilising hillsides, preventing erosion or influencing microclimates.

In the risk assessment it is important to understand the characteristics of the tree that is being transformed and its role in its range of environments. OECD (2012a) has now produced descriptions of many of the major species, which can provide a starting point for this evaluation. The risk assessment should then determine the impacts of the newly introduced GM traits on the tree and whether the traits will affect any of the environmental interactions associated with the non-GM tree or introduce new interactions with biota or receiving environments.

Risk assessments will need to carefully consider the likelihood of gene flow and spread of GM trees into the broader environment and the consequences for the ecology of potential receiving environments (Hoenicka \& Fladung 2006). In doing this, risk assessors will have to consider the time scale for these effects to occur and may have to develop models in order to assess potentia outcomes (DiFazio et al. 2004, Brunner et al 2007, Bialozyt 2012). Some of these factors have also been taken into consideration in the risk assessment of GM trees under the Cartagena Protocol on Biosafety (see http:// bch.cbd.int/onlineconferences/guidance_ra. shtml).

In order to restrict gene flow and manage impacts on natural and semi-natural environments, GM forest trees are most likely to be grown in specific plantation systems where flowering and seeding are managed. However, the environmental impacts of any new cultivation and management systems will need to be assessed and compared with the traditional systems they are replacing (Firbank 2008). In addition, GM orchard fruit tree cultivation techniques may also differ from conventional systems and any management changes require assessment for their environmental consequences.

The characteristics of trees also have implications for design of field trials for the purpose of determination of the stable expression and heritability of the modified trait etc. In addition, the choice of tree comparators and spectrum of available tree varieties with commercial use may be more limited. Therefore, there are methodological challenges to be solved in the data generation for the ERA such as the number of generations needed to test the genetic stability of the inserts (Ahuja 2009), the number and design of field trials for compositional, phenotypic, protein expression analysis and environmental impacts, and the use of different varieties or provenances to estimate current variation in commercial systems.

It is likely that further discussions will be needed on the types of studies required for providing safety data to be used in the RA of GM trees and their products, in order to provide further clarifications and guidance that complements the already existing EFSA guidance documents (Fladung et al. 2012).

\section{Conclusions}

In conclusion, the current EU regulatory framework on GMOs also applies to GM trees. The GM plant guidance documents developed by EFSA provide useful information on risk assessment of GM trees for applicants and risk assessors. However, the biology of GM fruit and forest trees and their management practices may call for some changes in the data types, collection, and analysis to support the risk assessment. Given the long generation time of GM trees, it becomes particularly important that hazard identification is initiated at an early stage and that data are collected that are relevant to the time scale of tree life cycles.

\section{Acknowledgements}

We acknowledge the EU Cost action FP0905 "Transgenic trees - The science behind future EU policy, regulations and safety assessments" for providing a forum for discussion on the biosafety of GM trees, and Sylvie Mestdagh for providing comments on the manuscript.

Part of this work has been presented at the "Fourth Biosafety Workshop" of the COST Action FP0905, held in Brasov (Romania) on October $25^{\text {th }}, 2012$.

The views or positions expressed in this article correspond to the authors and are not, and cannot be regarded as representing the position, the views or the policy of EFSA.

\section{References}

Ahuja RM (2009). Transgene stability and dispersal in forest trees. Trees 6: 1125-1135. - doi: 10.1007/s00468-009-0362-8

Bialozyt R (2012). Gene flow in poplar - experiments, analysis and modeling to prevent transgene outcrossing. iForest 5: 147-152. - doi: 10.3832/ifor0618-005

Brunner A, Li J, DiFazio SP, Shevchenko O, Montgomery BE, Mohamed R, Wei H, Ma C, Elias AA, VanWormer K, Strauss S (2007). Genetic containment of forest plantations. Tree Genetics and Genomes 3: 75-100. - doi: 10.1007/ s11295-006-0067-8

Codex Alimentarius (2009). Foods derived from modern biotechnology. Codex Alimentarius Commission, Joint FAO/WHO Food Standards Programme, Rome. [online] URL: http://www.fao.org/docrep/011/a1554e/a1554e00.htm

DiFazio SP, Slavov, GT, Burzyk J, Leonardi S, Strauss SH (2004). Gene flow from tree plantations and implications for transgenic risk assessment. In: "Plantation Forest Biotechnology for the $21^{\text {st }}$ Century" (Walter C, Carson M eds). Research Signpost, India, pp. 405-422.

EC (2001). Directive 2001/18/EC of the European Parliament and of the Council of 12 March 2001 on the deliberate release into the environment of genetically modified organisms and repealing Council Directive 90/220/EEC. Official Journal of the European Union, L106, pp. 1-39.

EC (2002). Commission Decision (2002/623/EC) of 24 July 2002 establishing guidance notes supplementing Annex II to Directive 2001/18/EC of the European Parliament and of the Council on the deliberate release into the environment of genetically modified organisms and repealing Council Directive 90/220/EEC. Official Journal of the European Union, L 200, pp. 22-33.

EC (2003). Regulation (EC) No $1829 / 2003$ of the European Parliament and of the Council of 22 September 2003 on genetically modified food and feed. Official Journal of the European Union, L 268, pp. 1-23.

EFSA (2009). Scientific opinion on guidance for the risk assessment of genetically modified plants used for non-food or non-feed purposes. EFSA Journal 1164: 1-42. - doi: 10.2903/j.efsa. 2009.1164

EFSA (2010). Guidance on the environmental risk assessment of genetically modified plants. EFSA Journal 8: 1879. - doi: 10.2903/j.efsa.2010.1879 EFSA (2011a). Scientific opinion on guidance for risk assessment of food and feed from genetically modified plants. EFSA Journal 9: 2150. doi: $10.2903 /$ j.efsa.2011.2150

EFSA (2011b). Guidance on the Post-Market Environmental Monitoring (PMEM) of genetically modified plants. EFSA Journal 9: 2316. - doi: 10.2903/j.efsa.2011.2316

Firbank LG (2008). Assessing the ecological impacts of bioenergy projects. Bioenergy Research 1: 12-19. - doi: 10.1007/s12155-007-9000-8 Fladung M (2011). Genetically modified trees for a sustainable, environmentally responsible and resource-saving production of wood for energy 
production. Gesunde Planzen 63: 101-110. - doi: 10.1007/s10343-011-0253-y

Fladung M, Altosaar I, Bartsch D, Baucher M, Boscaleri F, Gallardo F, Häggman H, Hoenicka H, Nielsen K. M, Paffetti D, Séguin A, Stotzky G, Vettori C (2012). European discussion forum on transgenic tree biosafety. Nature Biotechnology 30: 37-38. - doi: 10.1038/nbt.2078

Harfouche A, Meilan R, Altman A (2011). Tree genetic engineering and applications to sustainable forestry and biomass production. Trends in Biotechnology 29: 9-17. - doi: 10.1016/j.tibtech. 2010.09.003

Harfouche A, Meilan R, Kirst M, Morgante M, Boerjan W, Sabatti M, Scarascia Mugnozza G (2012). Accelerating the domestication of forest trees in a changing world. Trends in Plant Science 17: 64-72. - doi: 10.1016/j.tplants.2011. 11.005
Hoenicka H, Fladung M (2006). Biosafety in Populus spp. and other forest trees: from nonnative species to taxa derived from traditional breeding and genetic engineering. Trees 20: 131144. - doi: 10.1007/s00468-005-0023-5

Kikuchi A, Watanabe K, Tanaka Y, Kamada H (2008). Recent progress on environmental biosafety assessment of genetically modified trees and floricultural plants in Japan. Plant Biotechnology 25: 9-15. - doi: 10.5511/plantbiotechnology. 25.9

OECD (2012a). Safety assessment of transgenic organisms: OECD Consensus Documents. Web site, OECD, Paris. [online] URL: http://www. oecd.org/document/15/0.3746,en 264934385 37336335_1_1_1_1.00.html

OECD (2012b). OECD guidelines for the testing of chemicals. Web site, OECD, Paris. [online] URL: http://www.oecd.org/document/40/0.3746, en_2649_34377_37051368_1_1_1_1.00.html Walter C, Fladung M, Boerjan W (2010). The 20year environmental safety record of GM trees. Nature Biotechnology 28: 656-658. - doi: 10.1038/nbt0710-656

Whitham TG, Bailey JK, Schweitzer JA, Shuster SM, Bangert RK, LeRoy CJ, et al. (2006). A framework for community and ecosystem genetics: from genes to ecosystems. Nature Reviews Genetics 7: 510-523. - doi: 10.1038/nrg1877

\section{Footnotes}

[1] In the EU system, a Directive is a legislation whose objectives must be achieved through national legislations developed independently by each Member State. In contrast, a Regulation sets out the means to reach its own objective and does not require any implementing measures at the national level. 